\title{
An insulinoma presenting with reactive hypoglycaemia
}

\author{
H. CONNOR \\ M.B., M.R.C.P. (UK) \\ J. H. B. SCARPELLO \\ M.B., M.R.C.P. (UK) \\ Departments of Therapeutics and Medicine, Royal Infirmary, Sheffield S6 3DA
}

\begin{abstract}
Summary
A 57-year-old woman presented with symptoms which were cured by the removal of an insulinoma. The case was atypical in that symptomatic hypoglycaemia occurred only after meals or glucose administration but never during fasting, and thus if plasma insulin activity had not been measured an incorrect diagnosis of reactive hypoglycaemia might have been made on the basis of symptoms and oral glucose-tolerance test. Reactive hypoglycaemia resulted from an increased rate of glucose assimilation and possibly also from a decreased rate of gluconeogenesis due to the immense insulin secretion provoked by glucose or food.

The findings suggest that a diagnosis of reactive hypoglycaemia should not be made until the possibility of an insulinoma has been excluded by measurement of plasma insulin activity during a period of hypoglycaemia.
\end{abstract}

\section{Introduction}

Hypoglycaemia is often classified as fasting or reactive. The typical patient with an insulinoma will become hypoglycaemic on one or more of 3 occasions following an overnight fast, and after $72 \mathrm{hr}$ of fasting more than $98 \%$ of patients with an insulinoma will have developed symptomatic hypoglycaemia (Marks, 1974). In patients with essential reactive hypoglycaemia, the blood glucose concentration is always normal after a 12-hr fast and, although it may be as low as $1.7 \mathrm{mmol} / 1$ after $72 \mathrm{hr}$, the patient remains asymptomatic (Marks, 1974); symptomatic hypoglycaemia in these patients is provoked by food or glucose but not by fasting. This distinction is usually helpful in the investigation of hypoglycaemia but it is not absolute and its rigid application may lead to diagnostic errors. For example, an insulinoma occasionally presents with reactive hypoglycaemia, as described in this report.

\section{Case report}

A 57-year-old woman presented with a 7-year history of episodes of flashing lights in the periphery

* Correspondence: Dr H. Connor, County Hospital, Hereford. of her visual fields, followed after a few minutes by hot sweats and palpitations which persisted for up to $30 \mathrm{~min}$. These attacks usually occurred about 2-3 hr after food, and were not prevented by treatment with diazepam or propranolol. In the month before referral she described 3 occasions when her 'surrounding appeared distorted' and she wandered aimlessly. At these times she felt unable to speak and subsequently her speech became slurred and her lips numb. These symptoms occurred while at work and lasted from a few minutes to $3 \mathrm{hr}$. She was otherwise well.

When aged 36 years she had had an oophorectomy and hysterectomy for ovarian carcinoma, but there was no other relevant past history. She did not drink alcohol and was not taking any drugs at the time of investigation.

Physical examination was normal; height $171 \mathrm{~cm}$ and weight $65.6 \mathrm{~kg}$. Blood count, ESR and tests of renal, liver and thyroid function were normal. Blood glucose concentrations (glucose oxidase method) were between 3.9 and $5.6 \mathrm{mmol} / \mathrm{l}$ when the patient was asymptomatic. During a prolonged fast the blood glucose concentration was $3.5 \mathrm{mmol} / \mathrm{l}$ after $48 \mathrm{hr}$ and $2.6 \mathrm{mmol} / \mathrm{l}$ after $72 \mathrm{hr}$ but the patient remained asymptomatic throughout the fast. On the day after the fast she had an attack of sweating and palpitations $2 \mathrm{hr}$ after a meal; blood glucose concentration at this time was $1 \cdot 1 \mathrm{mmol} / 1$. The results of an oral glucose-tolerance test performed after an overnight fast are shown in Table 1. Reactive

\begin{tabular}{|c|c|c|}
\hline $\begin{array}{l}\text { Time } \\
(\mathrm{min})\end{array}$ & $\begin{array}{l}\text { Blood glucose } \\
(\mathrm{mmol} / \mathrm{l})\end{array}$ & $\begin{array}{l}\text { Plasma IRI } \\
(\mathrm{mu} . / \mathrm{l})\end{array}$ \\
\hline 0 & $4 \cdot 8$ & 29 \\
\hline 30 & $8 \cdot 2$ & 60 \\
\hline 60 & $11 \cdot 4$ & 245 \\
\hline 90 & 6.9 & - \\
\hline 120 & 3.8 & 305 \\
\hline 180 & $1 \cdot 3$ & 59 \\
\hline 240 & $1 \cdot 4$ & 27 \\
\hline
\end{tabular}


hypoglycaemia appeared after $180 \mathrm{~min}$ but plasma immunoreactive insulin (IRI) was disproportionately high at all times, thus confirming the diagnosis of insulinoma. Detailed metabolic investigations were performed before and after operation and will be described later.

At laparotomy a 2-cm tumour was found in the tail of the pancreas which was adherent to the spleen, and a partial pancreatectomy and splenectomy were performed. Histologically the tumour consisted of interlacing cords of uniform, small, cuboidal cells set in a densely fibrous amyloid-like stroma. Insulin was demonstrated in many of the cells by immunohistology using insulin antibodies labelled with peroxidase, and by electron microscopy which showed the typical membrane-bound granules with electron-dense contents (Frerichs and Creutzfeldt, 1976). These appearances are those of a benign insulinoma.

One month after operation she developed jaundice, which was of the mixed hepatocellular-cholestatic type. She had had no blood transfusions and tests for $\mathrm{HB}_{\mathrm{s}} \mathrm{Ag}$ were negative. She had been given both halothane and prochlorperazine but no definite cause could be established for her jaundice which recovered both clinically and biochemically within one month. There has been no recurrence of her original symptoms.

\section{Further investigations}

To study the nature of the hypoglycaemia which occurred following meals or glucose an intravenous glucose tolerance test $(50 \mathrm{ml}$ of $50 \%$ glucose) was performed after a $36-\mathrm{hr}$ fast. Venous blood samples were collected into tubes containing EDTA and trasylol for estimation of plasma IRI by the method of Hales and Randle (1963) and into bottles containing perchloric acid for estimation of glucose and other metabolites. The glucose content of these samples was measured by an autoanalyser adaptation of the hexokinase method of Bergmeyer et al. (1974) and lactate, pyruvate, alanine, hydroxybutyrate, aceto-acetate and glycerol were also measured by standard enzymatic methods, adapted to an autoanalyser (Lloyd, Buckle and Alberti, personal communication). The test was repeated 3 months after operation. The results are summarized in Table 2 and Figs 1-3.

In the pre-operative test there was mild fasting hypoglycaemia $(3.1 \mathrm{mmol} / \mathrm{l})$ which was asymptomatic and severe reactive hypoglycaemia (1.1 $\mathrm{mmol} / \mathrm{l}$ ), which was associated with palpitations, sweating and confusion. Hypoglycaemia did not occur in the postoperative study. The glucose assimilation coefficient $\left(\mathrm{K}_{\mathrm{g}}\right)$ changed from 2.97 before operation to 1.25 after. Fasting plasma IRI in the
TABLE 2. Blood glucose concentration and plasma immunoreactive insulin (IRI) activity in reponse to $25 \mathrm{~g}$ of intravenous glucose after a $36-\mathrm{hr}$ fast

\begin{tabular}{lccccc}
\hline & \multicolumn{2}{c}{ Pre-operative } & & \multicolumn{2}{c}{ Postoperative } \\
\cline { 2 - 3 } \cline { 5 - 6 } $\begin{array}{l}\text { Time } \\
\text { (min) }\end{array}$ & $\begin{array}{c}\text { Glucose } \\
(\mathrm{mmol} / \mathrm{l})\end{array}$ & $\begin{array}{c}\text { IRI } \\
(\mathrm{mu} . / \mathrm{l})\end{array}$ & & $\begin{array}{c}\text { Glucose } \\
(\mathrm{mmol} / \mathrm{l})\end{array}$ & $\begin{array}{c}\text { IRI } \\
(\mathrm{mu} . / \mathrm{l})\end{array}$ \\
\hline Fasting & $3 \cdot 1$ & 20 & & $4 \cdot 3$ & $<4$ \\
5 & $13 \cdot 2$ & 80 & & $15 \cdot 3$ & 23 \\
30 & $5 \cdot 4$ & & & $9 \cdot 8$ & \\
60 & $3 \cdot 7$ & $>500$ & & $7 \cdot 1$ & 8 \\
90 & $1 \cdot 1$ & 37 & & $5 \cdot 3$ & 5 \\
120 & $2 \cdot 5$ & 74 & & $4 \cdot 7$ & 5 \\
150 & $3 \cdot 2$ & & & 4.4 & \\
180 & 4.0 & & & 4.0 & \\
\hline
\end{tabular}

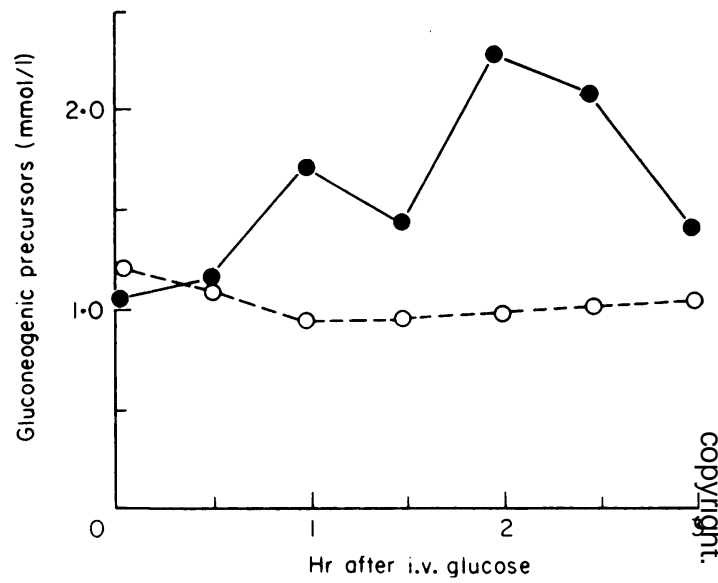

Fig. 1. Blood concentrations of gluconeogenic precursors (sum of lactate + pyruvate + alanine + glycerol) in response to $25 \mathrm{~g}$ of i.v. glucose following a $36-\mathrm{hr}$ fast, before and after removal of insulinoma. preoperative, $\mathrm{O}-\mathrm{O}$, post-operative.

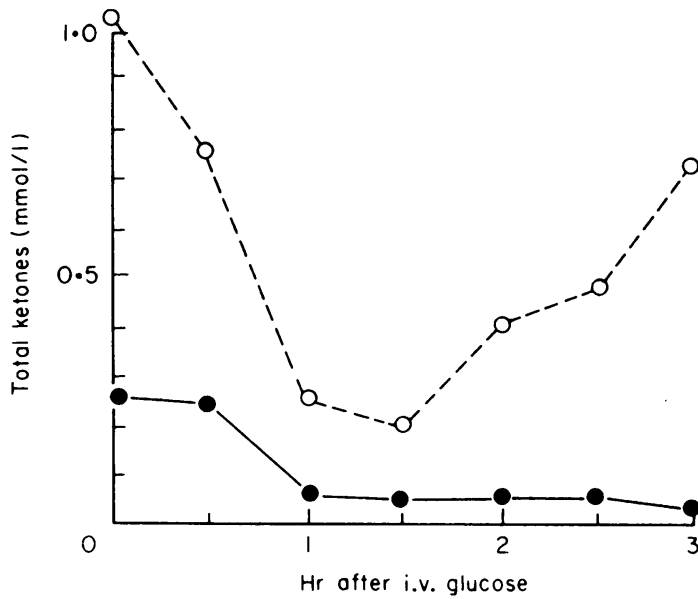

Fig. 2. Blood concentration of total ketones (hydroxybutyrate + acetoacetate) in response to $25 \mathrm{~g}$ of i.v. glucose following a 36-hr fast, before and after removal of insulinoma. - - , pre-operative, $\bigcirc-\bigcirc$, postoperative. 


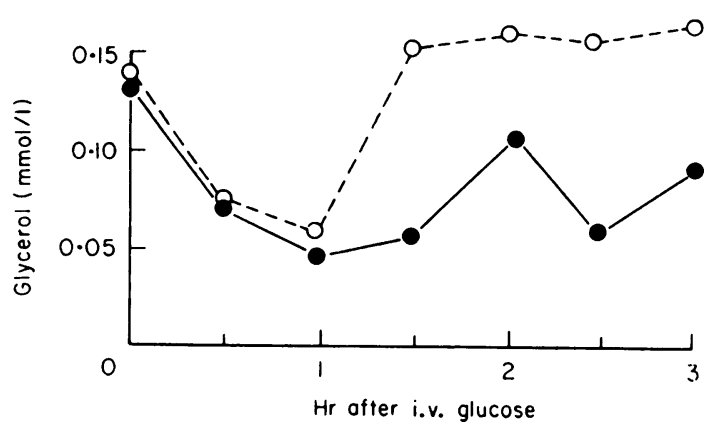

Fig. 3. Blood concentration of glycerol in response to $25 \mathrm{~g}$ of i.v. glucose following a 36-hr fast, before and after removal of insulinoma. - - , pre-operative, $\mathrm{O}-\mathrm{O}$, post-operative.

first study was inappropriately high $(20 \mathrm{mu} . / \mathrm{l})$ for the low blood glucose concentration, and rose excessively during the test to reach a peak of more than $500 \mathrm{mu} . / 1$ shortly before the onset of the reactive hypoglycaemia. Plasma IRI in the second study was normal.

During the first study there was a rise in the blood concentration of total gluconeogenic precursors (calculated as the sum of the lactate, pyruvate, alanine and glycerol concentrations). This rise preceded the onset of hypoglycaemia. No rise was seen postoperatively. Fasting glycerol concentrations and the changes after intravenous glucose were similar in the 2 studies, but the glycerol concentration remained low in the pre-operative study whereas postoperatively it rose rapidly to the fasting level. The fasting total ketone concentration (hydroxybutyrate plus aceto-acetate) in blood was much lower in the pre-operative study and was still low $3 \mathrm{hr}$ after intravenous glucose.

\section{Discussion}

The metabolic response to glucose in patients with an insulinoma is variable (Laurent, Debry and Floquet, 1971). Frerichs and Creutzfeldt (1976) state that insulinoma cells are relatively insensitive to a glucose stimulus, the sentitivity decreasing as cellular differentiation decreases. Nevertheless these authors report that 9 of 25 patients responded to an intravenous glucose load $(0.5 \mathrm{~g} / \mathrm{kg}$ body weight) with a maximal increase in plasma IRI which was above their normal limit of $120 \mathrm{mu}$./l. They do not say if any of their patients became hypoglycaemic, but Marks and Rose (1965) list fasting hypoglycaemia as one of the conditions which is associated with reactive hypoglycaemia. Reactive hypoglycaemia following a glucose load may be a normal finding (Marks, 1976) but it is thought to be pathological in this patient because it occurred after the same time interval and induced the same symptoms as the hypoglycaemia induced by food. Moreover, it is probable that the reactive hypoglycaemia is a consequence of the insulinoma because it disappeared after operation.

Power (1969) described a patient in whom a 72-hr fast failed to produce symptoms but who became hypoglycaemic and convulsed during 3 glucose tolerance tests. As in the present case the reactive hypoglycaemia was abolished by the removal of an insulinoma. However, reactive hypoglycaemia after glucose or meals in patients with proved insulinomas is not mentioned by Breidahl, Priestley and Rynearson (1956), 76 cases; Steinke (1971), 49 cases; Kavlie and White (1972), 21 cases; Clarke et al. (1972), 15 cases; or Frerichs and Creutzfeldt (1976), 29 cases. Symptomatic reactive hypoglycaemia would therefore appear to be a rare feature of insulinomas but this may be partly because the symptom has not been sought or because the diagnosis of insulinoma has been rejected when reactive hypoglycaemia was found. If plasma IRI had not been measured in the present case a diagnosis of essential reactive hypoglycaemia might have been made on the basis of the clinical features and the oral glucose tolerance test. Similarly, the glucose profile during the first i.v. glucose tolerance test is indicative of reactive hypoglycaemia rather than an insulinoma because the patient was asymptomatic before the glucose injection and a blood glucose concentration of $3.1 \mathrm{mmol} / \mathrm{l}$ is normal after a $36-\mathrm{hr}$ fast. However the measurement of plasma IRI is diagnostic of insulinoma because an insulin activity of $20 \mathrm{mu}$./1 is inappropriately high for a blood glucose concentration of $3.1 \mathrm{mmol} / 1$. Essential reactive hypoglycaemia is a diagnosis which is frequently made (Special Report, 1973) and although many such diagnoses are of dubious validity (Marks, 1976) some probably reflect organic disease. The present case report suggests that the possibility of an insulinoma should be excluded before making a diagnosis of essential reactive hypoglycaemia.

The immediate cause of the reactive hypoglycaemia in this patient was the excessive rise in plasma IRI in response to the glucose stimulus. The effect of this on the rate of glucose utilization is shown by the change in $\mathrm{K}_{\mathrm{g}}$ between the pre- and postoperative studies. It is also possible that the very high plasma IRI may have contributed to the hypoglycaemia by inhibition of gluconeogenesis. This possibility is supported by the finding that the plasma concentration of gluconeogenic precursors rose markedly in the first study but not in the second. Part of the rise in lactate and pyruvate concentrations may have resulted from increased catecholamine secretion, because it is known that hypoglycaemia due to exogenous insulin will stimulate secretion of adrenaline (Young and Landsberg, 1977) which will increase release of 
lactate from muscle (Baltzan et al., 1965). However, it can be seen from Fig. 1 and Table 2 that the increase in gluconeogenic precursors precedes the onset of hypoglycaemia and thus, although plasma adrenaline and noradrenaline concentrations were not measured, it is unlikely that the initial rise in concentration of gluconeogenic precursors was due to increased catecholamine secretion.

The effects of hyperinsulinism on other aspects of intermediary metabolism in this patient are shown by the suppression of lipolysis and ketogenesis which are reflected by the changes in blood glycerol and total ketone concentrations. This inhibition of lipolysis and ketogenesis limited the availability of oxidizable substrates when the patient was hypoglycaemic.

It is not known if there were any features of this patient's illness which made her especially prone to develop hypoglycaemia. Her insulinoma cells were well differentiated and such cells are more likely to secrete insulin in response to a glucose stimulus than are undifferentiated agranular cells (Frerichs and Creutzfeldt, 1976). Her diet seemed unremarkable but it is probable that the carbohydrate content of the diet will affect the response to glucose. It is, however, difficult to predict what the effect might be because there are conflicting reports of the influence of diet on the hypoglycaemic phase of the glucose tolerance curve. Thus Fabrykant (1955) found that reactive hypoglycaemia could occur in some subjects when given a low carbohydrate diet but not when on a high carbohydrate diet, whereas Murphy, Dustin and Bowman (1938) described the appearance of glucose-induced hypoglycaemia in an insulinoma patient who was changed from a normal to a high carbohydrate diet.

\section{Acknowledgments}

We are grateful to Dr J. D. Ward for permission to report details of this case, to Professor H. F. Woods for providing laboratory facilities, and to Professor V. Marks for the insulin assays reported in Table 1.

\section{References}

Baltzan, M.A., Andres, R., Cader, G. \& Zierler, K.L. (1965) Effects of epinephrine on forearm blood flow and metabolism in man. Journal of Clinical Investigation, 44, 80.

Bergmeyer, H.U., Bernt, E., Schmidt, F. \& Stork, H. (1974) D-Glucose. Determination with hexokinase and glucose-6-phosphate dehydrogenase. In: Methods of Enzymatic Analysis (Ed. by Bergmeyer, H.U.) 2nd English edn, vol. 3, p. 1196. Academic Press, London.

Breidahl, H.D., Priestley, J.T. \& Rynearson, E.H. (1956) Clinical aspects of hyperinsulinism. Journal of the American Medical Association, 160, 198.

Clarke, M., Crofford, O.B., Graves, H.A. \& Scott, W.H. (1972) Functioning beta cell tumors (insulinomas) of the pancreas. Annals of Surgery, 175, 956.

FABRYKANT, M. (1955) The problem of functional hyperinsulinism or functional hypoglycemia attributed to nervous causes. 2. The dietary and neurogenic factors. Diagnostic and therapeutic suggestions. Metabolism, 4, 480.

Frerichs, H. \& Creutzfeldt, W. (1976) Hypoglycaemia. 1. Insulin-secreting tumours. Clinics in Endocrinology and Metabolism, 5, 747.

HALES, C.N. \& RANDLE, P.J. (1963) Immunoassay of insulin with insulin-antibody precipitate. Biochemical Journal, 88, 137.

Kavlie, H. \& White, T.W. (1972) Pancreatic islet beta cell tumors and hyperplasia: experience in 14 Seattle hospitals. Annals of Surgery, 175, 326.

Laurent, J., Debry, G. \& Floquet, J. (1971) Hypoglycaemic Tumours. Excerpta Medica, Amsterdam.

MARKS, V. (1974) The investigation of hypoglycaemia British Journal of Hospital Medicine, 11, 731.

MARKs, V. (1976) Hypoglycaemia. 2. Other causes. Clinics in Endocrinology and Metabolism, 5, 769.

MARKS, V. \& Rose, C. (1965) Hypoglycaemia. Blackwelle Scientific Publications, Oxford.

MurPhy, R.G., Dustin, C.C. \& Bowman, R.O. (1938) Hyperinsulinism due to adenoma of the pancreas. Journal of Laboratory and Clinical Medicine, 24, 1050.

Power, L. (1969) A glucose-responsive insulinoma. Journal of the American Medical Association, 207, 893.

SPECIAL RePORT. (1973) Statement on hypoglycemia. Diabetes, 22, 137.

STEINKe, J. (1971) In: Joslin's Diabetes Mellitus (Ed. by Marble, A., White, P., Bradley, R.F. \& Krall, L.P.), 11 th edn, p. 797. Lea \& Febiger, Philadelphia.

Young, J.B. \& LANDSBERG, L. (1977) Catecholamines and intermediary metabolism. Clinics in Endocrinology and Metabolism, 6, 599. 